\title{
Print media coverage of research on passive smoking
}

\author{
Gail E Kennedy, Lisa A Bero
}

\begin{abstract}
Objective-To assess the extent and content of newspaper and magazine coverage of research on passive smoking. Design-Content analysis of newspaper and magazine articles.

Subjects-Articles reporting on passive smoking research published in newspapers $(n=180)$ or magazines $(n=92)$ between January 1981 and December 1994. Main outcome measures-Numbers of articles, conclusions of articles, sources quoted, numbers and characteristics of research studies cited, presence of tobacco advertising.

Results-The number of newspaper and magazine articles reporting on passive smoking research increased from four in 1981 to 57 in 1992 and 32 in 1994. Sixty-two per cent (168/272) of articles concluded that the research on passive smoking is controversial. Tobacco industry representatives were quoted significantly more often in newspaper articles $(52 \%, 94 / 180)$ than magazine articles $(12 \%, 11 / 92)$ $(p<0.0001)$. Of 121 different research studies cited in the lay press articles, only 15 were from tobacco-industry sponsored projects or publications. In magazines, acceptance of tobacco industry advertising was associated with the conclusion that research on passive smoking is controversial $(\mathrm{p}<0.0001)$.
\end{abstract}

Conclusions-Although research on the harmful effects of passive smoking accumulated between 1981 and 1994, lay press coverage of the research maintained that the science was controversial. Few research studies were cited to support the industry's claim that passive smoking is not harmful to health. However, tobacco industry representatives who were critical of the research methods used to study the health effects of passive smoking were frequently quoted.

(Tobacco Control 1999;8:254-260)

Keywords: environmental tobacco smoke; media; passive smoking

Institute for Health Policy Studies

L A Bero

Correspondence to: Dr LA Bero, University of California,

San Francisco, 3333
California Street, Suite 420, Box 0613, San Francisco, California 94118, USA; bero@medicine.ucsf.edu

Received 27 August 1998 Revision received 2 February 1999

Accepted 23 February 1999 disseminating scientific research disputing the association between cigarette smoking and disease. ${ }^{4}$ The successful public relations campaigns of the industry, as well as its influence on the lay media through advertising dollars, are likely to have affected lay press coverage of the harmful effects of tobacco. ${ }^{5}$

Although scientific evidence now strongly suggests that exposure to passive smoke is also harmful, public opinion about the adverse health effects has been slow to change. In 1981, two ground-breaking studies showed an association between passive smoking and lung cancer, ${ }^{67}$ and in 1986 two scientific consensus reports were published on the harmful effects of exposure to passive smoke. ${ }^{8}{ }^{9}$ By 1988 studies demonstrated an association between passive smoking and heart disease. ${ }^{10-12}$ Finally, in 1992, the United States Environmental Protection Agency (EPA) classified passive smoke as a Group A (known human) carcinogen. ${ }^{13}$

(The tobacco industry sued the EPA over the findings of the risk assessment of passive smoking. In July 1998, Judge Osteen vacated the risk assessment on procedural grounds, but did not conclude that the science of the report was invalid [Flue-cured Tobacco Cooperative Stabilization Corporation $v$ EPA. The Osteen decision in the United States District Court for the Middle District of North Carolina Winston-Salem Division (17 July 1998). Accessed on 3 September 1998 and 28 January 1999 at http://www.tobacco.org.Documents/ 980717osteen.html]

Thus, between 1981 and the early 1990s, the scientific community reached a consensus that passive smoking is associated with adverse health effects.

The purpose of this paper was to assess the extent and content of newspaper and magazine coverage of passive smoking research. We determined whether the research on passive smoking was portrayed as controversial and, if so, whether the portrayal of controversy decreased over time. We collected data on several journalistic devices that can be used to generate the idea of controversy. ${ }^{14}{ }^{15}$ For example, we recorded the topic of research covered because the association of passive smoking and adverse health outcomes could be more controversial for some diseases than others. We recorded who was quoted in the articles because journalists could generate controversy through their selection of sources. We report the frequency, source, type, and conclusions of the scientific studies cited because journalists could generate controversy by selectively citing certain types of studies. 
We determined whether the scientific studies cited in the lay press found that passive smoking was harmful (a "positive" study) or not (a "negative" study) because research on the coverage of other environmental risks has shown that the lay press is more likely to report positive than negative studies. ${ }^{16}{ }^{17}$

In addition to characterising the journalistic devices described above, we hypothesised that research on passive smoking sponsored by the tobacco industry would be cited in newspapers and magazines to dispute scientific findings on the adverse health effects of passive smoking. Just as the tobacco industry has funded research suggesting that smoking is not harmful, it has sponsored and disseminated research suggesting that passive smoking is not harmful. The industry's research, concluding that passive smoking is not harmful, has been methodologically poor and used in efforts to delay regulatory action. ${ }^{18-20}$

We report the content of newspaper and magazine articles separately. We hypothesised that magazine coverage would differ from newspaper coverage for two reasons: (a) magazine articles tend to be longer and therefore have opportunity for more detailed coverage and more citation of individuals and (b) more magazines than newspapers during the time period of our study accepted tobacco advertising. We examined the relationship between tobacco industry advertising and coverage of passive smoking research because, in magazines, a lack of coverage of the adverse effects of smoking is associated with the acceptance of tobacco advertising. ${ }^{52122}$

\section{Methods}

We conducted a descriptive, cross-sectional content analysis of newspaper and magazine articles reporting on passive smoking research between January 1981 and December 1994.

SAMPLE SELECTION

Inclusion/exclusion criteria

We included newspaper and magazine articles published between January 1981 and December 1994 that reported on research on the health effects of passive smoking. We defined research as any basic science, epidemiological, clinical, or review study, including government reports. Articles that discussed litigation or workplace smoking regulation without discussing passive smoking research were excluded. We began the search in 1981 because the first major studies showing an association between passive smoke and lung cancer was published in that year. ${ }^{67}$ We excluded duplicate articles, opinion pieces, editorials, and letters to the editor.

\section{Newspaper search strategy}

Using an adaptation of a previously published method, ${ }^{16}$ we retrieved articles by searching three commercial online services (Nexis, Datatimes, and Knowledge Index-a Dialog database) using 12 keyword phrases for the term "passive smoking". We limited our newspaper sample to the five papers with the highest average daily circulation rates in the United
States (New York Times, Washington Post, USA Today, Wall Street Fournal, and Los Angeles Times) because our preliminary search found that these newspapers published most of the articles describing research on passive smoking and that their articles were likely to be reprinted in other newspapers. We chose circulation rate as an inclusion criterion because it is an objective measure of the number of people potentially exposed to a news article. Our search identified 1474 full text articles which were independently screened by two reviewers to determine which articles met our inclusion criteria. Disagreements regarding included articles $(n=8)$ were adjudicated by the principal investigator. A total of 180 newpaper articles met our inclusion criteria for the content analysis.

\section{Magazine search strategy}

Five electronic databases (Dialog, EBSCO, Melvyl Mags, Nexis, and ABI/Inform) were searched using 12 keywords for "passive smoking" for articles from general and specialised magazines for lay audiences. We identified 233 full text articles which were independently screened by two reviewers to determine which articles met our inclusion criteria. The full text of nine articles could not be located in any of the electronic databases or at the San Francisco Public Library. Disagreements regarding included articles $(n=6)$ were adjudicated by the principal investigator. A total of 92 magazine articles met our inclusion criteria for the content analysis.

\section{CONTENT ANALYSIS}

A coding instrument for the content analysis was developed, pre-tested, and tested for percent agreement between the raters. ${ }^{23}{ }^{24}$ All 180 newspaper articles and 92 magazine articles were coded independently by a research associate and doctoral student. The student did not have extensive knowledge of the literature on passive smoking, disclosed no financial conflict of interest, and was blinded to the study hypotheses. A written protocol was used and a training session was conducted. Interrater agreement was determined for all articles analysed and ranged from 93\% to $100 \%$ for each question in the instrument. Discrepancies were adjudicated by the principal investigator.

\section{Extent and characteristics of articles}

To assess the extent and prominence of coverage of research on passive smoking, we recorded the number of articles published each year, the length of each article, and, for newspapers, the section in which each article was published. For magazines, we coded the readership according to Urlich's International Periodicals Directory. ${ }^{25}$ We recorded the author(s) of each article and any affiliation(s) listed.

\section{Controversy in articles}

The coders answered "yes" or "no" to the questions: (a) "Overall, is the reader left with the impression that passive smoking is a health 
hazard?" and (b) "Overall, is the reader left with the impression that there is continuing controversy about passive smoking research?" regardless of whether or not they felt that passive smoking was a health hazard. To determine if there was any change in the degree of controversy over time, we examined the answer to the question about controversy by year.

To examine how an impression of controversy might be generated in the articles, we recorded the topic of research covered because the association of passive smoking and adverse health outcomes could be more controversial for some diseases than others. We recorded who was quoted in the articles because journalists could generate controversy through their selection of sources.

We report the frequency, source, type, and conclusions of the scientific studies cited because journalists could generate controversy by selectively citing certain types of studies.

Topics covered in articles

We coded articles as discussing one or more of the following topics: (a) lung cancer, (b) other cancers, (c) heart disease, (d) health effects in children, (e) respiratory conditions, or (f) other.

Sources quoted in articles

For each article, we recorded the number of quotes made about passive smoking research by (a) public health or government officials, (b) scientists, physicians, or academicians, (c) non-smoker's rights advocates, (d) tobacco industry representatives, (e) smoker's rights advocates, or (f) other or no affiliation given.

Frequency, source, type and conclusions of cited scientific studies

To determine which scientific studies and reports were cited in the newspaper and magazine articles, we recorded the study name and author, if available, for each scientific study cited. We searched Medline by author name or keywords to identify the source articles for each cited study. A total of 90 scientific studies were cited in the newspaper sample and 87 studies were cited in the magazine sample.

To assess the characteristics of the scientific studies cited in the newspaper articles, we obtained copies of 88 of the 90 scientific studies identified in the sample from the University of California Libraries, the Government Printing Office, or directly from the study authors. We were not able to obtain copies of an unpublished study funded by the Tobacco Institute and an international report. We obtained copies of 77 of the 87 scientific studies cited in the magazine sample. We were not able to locate 10 citations with vague and incomplete identifying information. Overall, 121 different scientific studies were cited in the newspapers and magazines.

For each scientific study obtained, we coded publication type as a (a) journal, (b) symposium proceeding, (c) government sponsored report, or (d) other, to provide a rough indicator of publication quality. ${ }^{18}{ }^{26} \mathrm{Cita}-$ tions from journals were further coded using previously developed criteria ${ }^{27}$ by (a) type of article (original, review, letter to the editor, editorial, or abstract), (b) whether or not the article was peer reviewed, and (c) source of funding acknowledged in the publication.

To determine whether the newspaper and magazine articles were more likely to cite studies indicating that passive smoking is harmful to health than not harmful to health, we recorded the context in which each article discussed the cited scientific studies. A cited study was coded as (a) concluding that passive smoking is harmful, (b) concluding that passive smoking is not harmful, or (c) "mixed" if it was reported as having harmful and not harmful findings or inconclusive findings.

\section{Tobacco advertising}

We examined the relationship between tobacco industry advertising and conclusions of the articles. To determine whether the newspapers in our sample accepted tobacco industry advertising, we first contacted the editorial office of each newspaper by mail and telephone. We received no responses and, therefore, searched the entire paper by hand for tobacco product advertising on a randomly selected day in $1981,1985,1991$, and 1994. If no tobacco product advertisements were identified, the search was continued for the following six days. If any tobacco product advertising was identified the newspaper was classified as accepting tobacco advertising.

To determine whether the magazines in our sample accepted tobacco advertising, we first determined whether the magazine was on a published list of magazines that refuse tobacco product advertising. ${ }^{28}$ If the magazine was not on the list, we posted a question on the Magazine Publishers of America website (www.mediafinder.com) asking whether the magazine accepted tobacco advertising. For 10 magazines for which we could not obtain information from either of these sources, we searched the entire magazine by hand for tobacco product advertising on a randomly selected day in $1981,1985,1991$, and 1994. If no tobacco product advertisements were identified, the next two issues of the magazine were searched. If any tobacco product advertising was identified the magazine was classified as accepting tobacco advertising.

\section{ANALYSIS}

Differences in proportions were analysed using the $z$ statistic, $\chi^{2}$ statistic, Mann-Whitney Rank Sum test, or Fisher's Exact test as appropriate.

\section{Results}

EXTENT AND CHARACTERISTICS OF ARTICLES As shown in the figure, the number of newspaper and magazine articles reporting on passive smoking research increased between 1981 and 1994. About half (88/180) of the newspaper articles were 500 words or more; $42 \%(39 / 92)$ of the magazine articles were 1000 words or more.

Sixty-three per cent $(114 / 180)$ of the newspaper articles were located in the national 


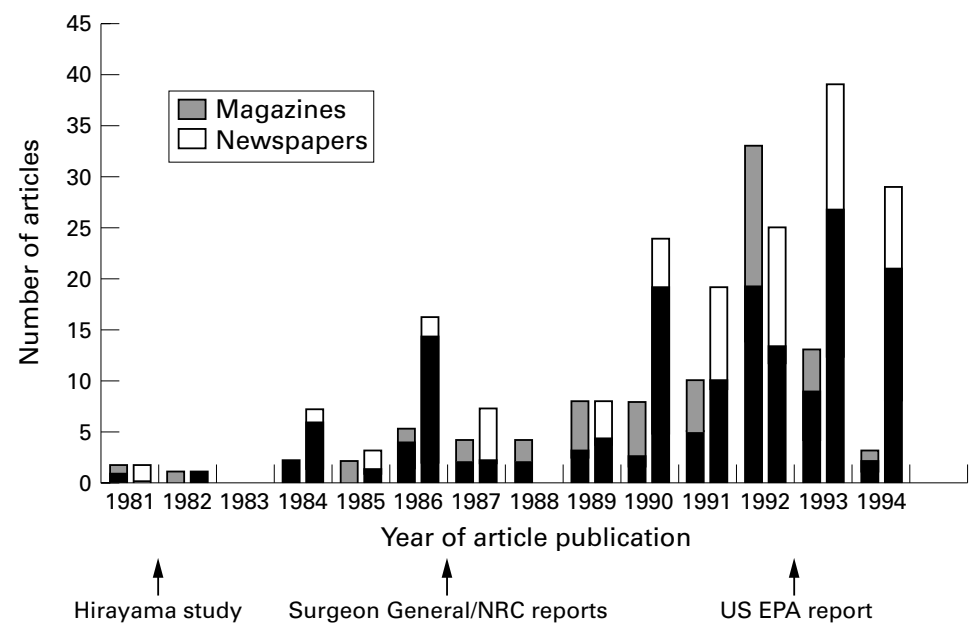

The black part of each bar represents the number of articles that conclude that research on passive smoking is controversial. The arrows indicate the publication dates of four major reports on the adverse health effects of passive smoking. Hirayama = (7); Surgeon General report $=(8), N R C$ report $=(9), U S E P A$ report $=(13)$.

or local news section, $13 \%(24 / 180)$ were located in the health or science section, and $24 \%(43 / 180)$ were distributed across the business, feature, and other sections. Forty-two per cent $(76 / 180)$ of the articles were on the front page of the section in which they were located. Most of the 92 magazine articles were published in general interest $(n=31)$, health/science $(n=21)$, or politics/policy $(n=$ 12) magazines. The remainder were published in business, home, or consumer magazines.

There was no overlap between newspaper and magazine journalists reporting on passive smoking research. Seventy-six per cent $(137 / 180)$ of the newspaper articles were authored by newspaper staff writers; the remainder were from anonymous wire service reports. Fifteen newspaper journalists authored three or more articles on passive smoking research, whereas no magazine journalists wrote more than three articles on passive smoking research. Four of the magazine articles were authored by individuals with disclosed tobacco industry affiliations. ${ }^{29-32}$ In addition, we found one article written by a United States surgeon general ${ }^{33}$ and one written by a well-known independent researcher. ${ }^{34}$

CONTROVERSY IN ARTICLES

Sixty-six per cent $(118 / 180)$ of the newspaper articles and 54\% (50/92) of the magazine articles gave the impression that there is continuing controversy about passive smoking

Table 1 Sources quoted in articles reporting passive smoking research

\begin{tabular}{|c|c|c|c|c|c|c|}
\hline \multirow[b]{2}{*}{ Type of person quoted } & \multicolumn{2}{|c|}{$\begin{array}{l}\text { Magazine articles } \\
(n=92)\end{array}$} & \multicolumn{2}{|c|}{$\begin{array}{l}\text { Newspaper articles } \\
(n=180)\end{array}$} & \multirow[b]{2}{*}{$z$} & \multirow[b]{2}{*}{$p$} \\
\hline & $\%$ & (n) & $\%$ & $n$ & & \\
\hline Public health/government officials & 32 & $(30)$ & 56 & $(101)$ & 3.62 & $<0.0001$ \\
\hline Scientists/physicians/academicians & 29 & $(27)$ & 46 & $(82)$ & 2.57 & 0.01 \\
\hline Non-smoker's rights advocates & 24 & $(22)$ & 4 & $(8)$ & 4.83 & $<0.0001$ \\
\hline Tobacco industry representatives & 12 & (11) & 52 & $(94)$ & 6.28 & 0.0001 \\
\hline Smoker's rights advocates & 2 & (2) & 0 & (0) & 1.12 & 0.26 \\
\hline Other or no affiliation & 3 & (3) & 0 & $(0)$ & 1.70 & 0.09 \\
\hline
\end{tabular}

Percentages add to more than 100 because the categories are not mutually exclusive. An article was rated as quoting someone in a particular category if at least one person in that category was quoted. Differences in proportions were analysed using the $z$ statistic. research $(z$ statistic $=1.80 ; \mathrm{p}=0.07)$. However, 94\% (170/180) of newspaper articles and $79 \%(73 / 92)$ of magazine articles gave the impression that passive smoking is a health hazard $(z$ statistic $=3.53 ; \mathrm{p}<0.0001)$. As shown in the figure, the proportion of articles leaving the impression that the research is controversial did not diminish over time as more research consensus reports on passive smoke accumulated.

The criticisms of research methods were generally non-specific. For example, several articles discussed the methodology used for the United States Environmental Protection Agency (EPA) risk assessment of passive smoking. ${ }^{13}$ The EPA risk assessment classified passive smoke as a Group A (known human) carcinogen based on a methodology that combined the results of 30 individual research studies. One article declared that the EPA risk assessment was invalid because "none of the environmental tobacco smoke epidemiological studies is a 'high validity' randomized prospective study" and "the data from the various studies cannot be legitimately combined." ${ }^{\prime 3}$ In addition, the article criticised all research studies on passive smoking as "of questionable quality and validity . . . because they have not been controlled adequately for numerous confounding factors potentially important to the development of these diseases." 30 One of the articles giving these non-specific criticisms was written by a tobacco-industry affiliated scientist whose affiliation and funding source were not acknowledged in the magazine article. $^{30}$

\section{TOPICS COVERED IN ARTICLES}

There were no significant differences between the types of health risks related to passive smoking covered in magazine and newspaper articles. More than half of the newspaper (63/92) and magazine (129/180) articles reported on studies of the association of passive smoking and lung cancer, followed by reports on health conditions in children in 46/92 newspaper and 86/180 magazine articles. The remaining articles reported on cardiovascular disease, cancers other than lung cancer, and other respiratory effects.

SOURCES QUOTED IN ARTICLES

As shown in table 1, public health and government officials were quoted most often in newspaper and magazine articles. Although the newspaper articles were shorter, tobacco industry representatives, public health/ government officials, and scientists/physicians/ academicians were quoted significantly more often in newspaper than magazine articles. The tobacco industry officials were consistently critical of research showing an association between passive smoking and disease.

FREQUENCY, SOURCE, TYPE, AND CONCLUSIONS OF CITED SCIENTIFIC STUDIES

Overall, scientific studies were cited 348 times in the newspaper articles and 218 times in the magazine articles. Although magazine articles were longer, there was no difference between 
Table 2 Characteristics of citations

\begin{tabular}{|c|c|c|c|c|}
\hline \multirow[b]{2}{*}{ Source of citation } & \multicolumn{2}{|c|}{$\begin{array}{l}\text { Citations in magazines } \\
(n=77)\end{array}$} & \multicolumn{2}{|c|}{$\begin{array}{l}\text { Citations in newwspapers } \\
(n=88)\end{array}$} \\
\hline & $\%$ & $n$ & $\%$ & $n$ \\
\hline Medical/scientific journal & 62 & $(48)$ & 70 & $(62)$ \\
\hline Government report & 23 & (18) & 27 & $(24)$ \\
\hline Symposium/conference proceeding & 5 & (4) & 1 & $(1)$ \\
\hline Book & 6 & (5) & 0 & $(0)$ \\
\hline Tobacco industry position paper & 1 & (1) & 0 & $(0)$ \\
\hline \multirow[t]{2}{*}{ Dissertation } & & (1) & 1 & (1) \\
\hline & \multicolumn{4}{|c|}{$\chi^{2}=9.75 ; \mathrm{p}=0.03$} \\
\hline
\end{tabular}

Differences between magazines and newspapers were analysed using the $\chi^{2}$ statistic.

the numbers of scientific studies cited in magazine and newspaper articles $(\mathrm{p}=0.07)$. About half of the newspaper (98/180) and magazine (49/92) articles cited only one passive smoking study per article. Only 32 of 180 newspaper articles and 28 of 92 magazine articles cited three or more scientific studies per article.

In addition, most scientific studies were cited only a few times each in the entire sample. Only six studies were cited more than 10 times in the newspaper articles and only four studies were cited more than 10 times in the magazine sample. All of these most frequently cited studies were systematic reviews of the scientific literature, rather than original research studies. The single most frequently cited study was the EPA risk assessment of passive smoking ${ }^{13}$ which accounted for $14 \%$ of all study citations in newspapers and $17 \%$ of all study citations in magazines. In the newspaper articles, the EPA report was cited as concluding that passive smoke is harmful 45 times, and as an inconclusive study four times. In the magazine articles, the EPA report was cited as concluding that passive smoke is harmful 36 times, and as an inconclusive study twice.

Most of the studies cited in the newspaper and magazine articles were cited as concluding that passive smoking is harmful. Eighty-eight per cent (305/348) of the citations in newspapers were cited as concluding that passive smoking is harmful, $7 \%(25 / 348)$ of the citations were cited as concluding that passive smoking is not harmful, and $5 \%(18 / 348)$ were cited as having "mixed" conclusions. Eighty-three per cent $(181 / 218)$ of the citations in magazines were cited as concluding that passive smoke is harmful, $10 \%(21 / 218)$ of the citations were cited as concluding that passive smoke is not harmful, and $7 \%(16 / 218)$ were cited as having "mixed" conclusions.

Table 3 Association of tobacco product advertising and conclusions of lay press articles

\begin{tabular}{lll}
\hline & $\begin{array}{l}\text { Articles concluding that passive } \\
\text { smoking is a health hazard } \\
n(\%)\end{array}$ & $\begin{array}{l}\text { Articles concluding that research on } \\
\text { passive smoking is controversial } \\
n(\%)\end{array}$ \\
Presence of tobacco advertising \\
\hline Magazines $(\mathrm{n}=92)$ & & $38(72)$ \\
Present $(\mathrm{n}=53)$ & $36(68)$ & $12(31)$ \\
Not present $(\mathrm{n}=39)$ & $37(95)$ & $\mathrm{p}<0.0001$ \\
Newspapers $(\mathrm{n}=180)$ & $\mathrm{p}=0.002$ & $52(59)$ \\
Present $(\mathrm{n}=88)$ & $86(98)$ & $66(72)$ \\
Not present $(\mathrm{n}=92)$ & $84(91)$ & $\chi^{2}=2.65 ; \mathrm{p}=0.07$ \\
& $\chi^{2}=2.42 ; \mathrm{p}=0.12$ &
\end{tabular}

For magazines, differences between articles from magazines with or without tobacco advertising were analysed using Fisher's Exact test. For newspapers, data were analysed using the $\chi^{2}$ statistic.
As shown in table 2, most of the studies cited in newspaper or magazine articles were from medical/scientific journals, followed by government sponsored reports. There were no differences in the types or peer review status of journal articles cited in newspapers and magazines $\left(\chi^{2}=0.91 ; p=1.00\right)$. Of the 110 journal articles cited in newspapers, $79 \%(87 / 110)$ were publications of original research, $13 \%$ $(14 / 110)$ were review articles, $6 \%(7 / 110)$ were editorials, and $2 \%(2 / 110)$ were reports of conference proceedings. Ninety-nine per cent of the journal articles cited (109/110) were from peer reviewed journals.

Fifteen studies or publications sponsored by the tobacco industry were found among the studies cited in newspaper and magazine articles. Only $66 \%$ (73/110) of the journal articles cited acknowledged their funding source(s). Of the journal articles that disclosed their funding sources, six were funded at least partially by the Center for Indoor Air Research (a research organisation sponsored by the tobacco industry), ${ }^{35-40}$ two by tobacco companies, ${ }^{41}{ }^{42}$ and one by the Tobacco Research Council. ${ }^{43}$ Another journal article that was a critique of scientific methods used to conduct risk assessments of passive smoking was written by a researcher affiliated with the tobacco industry. ${ }^{44}$ In addition to the journal articles, three symposium proceedings sponsored by the tobacco industry, ${ }^{45-47}$ and one public relations piece published by the Tobacco Institute ${ }^{48}$ were cited. Additional citations were of a book published by the Tobacco Institute. ${ }^{49} \mathrm{~A}$ dissertation that has been heavily cited by the tobacco industry in response to government requests for information was also cited in the newspaper and magazine articles. ${ }^{50}$

\section{TOBACCO ADVERTISING}

As shown in table 3, articles from magazines that accept tobacco advertising were less likely to conclude that passive smoking is a health hazard and more likely to conclude that the research on passive smoking is controversial than articles from magazines that refuse tobacco advertising. Table 3 also shows that there was no association between articles from newspapers that accept tobacco advertising and concluding that passive smoking is harmful or that research on passive smoking is controversial.

\section{Discussion}

Print media coverage of passive smoking research has increased over time and has been fairly prominent. Print news media articles can shape public opinion, influence policymakers, and influence the direction of scientific research, ${ }^{16}{ }^{51-54}$ thus the increasing coverage of passive smoking research may have contributed to growing public interest in this issue.

Even after strong scientific evidence existed supporting an association between passive smoking and disease, ${ }^{89}$ newspaper and magazine coverage continued to construct the conduct of research on passive smoking as controversial. This finding is similar to findings 
from analyses of media coverage of active smoking. ${ }^{3}$

In magazines, continuing emphasis on controversy might be explained by magazines' acceptance of tobacco product advertising. Advertising dollars may influence editorial coverage of passive smoking as demonstrated for other tobacco and health issues. ${ }^{52122}$

The continuing emphasis on controversy might also be explained by journalists' tradition of "balanced reporting". ${ }^{14}$ To present both sides of the passive smoking issue journalists, particularly in newspapers, routinely quoted tobacco industry spokespersons discussing vague methodological faults with scientific studies. ${ }^{55}$ By quoting tobacco industry sources as well as scientists, journalists may be suggesting that the opposing voices carry equal scientific weight. Furthermore, although journalists have claimed that they do not routinely seek opposing views when covering research that has been published in peer reviewed journals, ${ }^{56}$ we found that coverage of passive smoking research emphasised controversy even when most of the journal articles cited were peer reviewed. A recent editorial on health communication has challenged journalists to consider whether common principles of journalistic reporting, such as use of multiple sources and inclusion of various viewpoints, make the best news stories. ${ }^{57}$ The focus on controversy surrounding research methods is not consistently found in the news coverage of other health issues. For example, the research on the genetics of alcoholism was not presented as controversial in the lay press even after evidence disproving a genetic cause for alcoholism accumulated. ${ }^{17}$

The quotation of tobacco industry representatives, rather than the citation of scientific studies, was used by journalists to promote the idea of controversy. Only a few studies or publications sponsored by the tobacco industry were cited in the lay press articles. However, given that most of the journal articles that were cited did not disclose their funding source(s), we may be underestimating the total percentage of research, sponsored by the tobacco industry, which is cited in newspapers and magazines. In fact, one author of a journal article ${ }^{58}$ who had no disclosed funding source was identified in our earlier work as being affiliated with the tobacco industry. ${ }^{18} 26$

A third possible explanation for the maintenance of controversy in the articles might be the tobacco industry's efforts to influence media reporting rather than to provide data refuting research on passive smoking. The industry's strategy is described in a 1989 background paper on the activities of RJ Reynolds Tobacco Company, Philip Morris Tobacco Company, and the Tobacco Institute. ${ }^{59}$ According to the document, the Tobacco Institute (TI) was most involved in communicating with the media:

"TI is initiating a program of bringing foreign ETS [environmental tobacco smoke] scientists/ experts to appropriate scientific conferences for presentation of papers, and while they are here, get them to speak to U.S. media on research facts, misrepresentation. Would include editorial board briefings as well as media interviews.

"TI also plans to: Develop and distribute media ETS briefing book which will clarify the science on ETS, and distribute to key journalists. Assess and communicate the way journalists cover controversial scientific issues, especially ETS:

-Include 'white paper' re faulty reporting

- Find a columnist or professor of journalism to write articles on poor quality of scientific journalism

-Work with a professional journalism group to sponsor seminar on coverage of science in the media

"This information would be conveyed to key members of the media via editorial board meetings, informal discussions with reporters, etc., and the brochure would be provided as a reminder." ${ }^{59}$

As with other scientific research, only a portion of the scientific literature on passive smoking garners press attention. ${ }^{60}$ We identified 121 different scientific publications on the health effects of passive smoking cited in newspaper and magazine articles. However, in other research in which we conducted comprehensive searches to identify studies on the health effects of passive smoking, we found 382 original research articles and 106 review articles published during the same time period. ${ }^{19} 20$

The most frequently cited scientific studies in the lay press articles were systematic reviews rather than original research studies. The coverage of reviews, especially government reports, ${ }^{813}$ highlights their potential to influence public opinion and policy. Well conducted reviews can provide objective and critical summaries of massive amounts of data, ${ }^{61}$ although the conclusions of reviews on passive smoking are associated with their source of funding. ${ }^{19}$

We found only limited coverage of studies that did not find a statistical association between passive smoke exposure and adverse health effects. As more studies indicating that passive smoking is harmful (rather than indicating that it has no adverse effects) have been published in the medical literature, ${ }^{62}$ the lay press coverage accurately reflects the findings of research that is reported in scientific publications. The citation of studies finding an association between passive smoking and disease has been previously reported for coverage of passive smoking in Australian newspapers, ${ }^{63}$ as well as for coverage of other environmental risks. ${ }^{16}{ }^{17}$ This reporting of the studies finding an association between passive smoking and disease is potentially undermined by the emphasis on the controversy surrounding research on passive smoking.

In summary, although research on the harmful effects of passive smoking accumulated between 1981 and 1994, lay press coverage of the research maintained that the science was controversial. Few research studies were cited to support the industry's claim that passive smoking is not harmful to health. However, tobacco industry representatives who were critical of the research methods used to study 
the health effects of passive smoking were frequently quoted.

This study was supported by the Robert Wood Johnson Foundation (Award 024783). We thank Jody Ranck for coding articles for the content analysis; Deborah E Barnes, Ruth E Malone, Anastasia Misakian, and Veronica Yank who offered valuable insight at various stages of this project, the Writing Seminar at the Institute for Health Policy Studies, and Phillip Lollar who provided administrative assistance.

1 Wynder E, Graham EA. Tobacco smoking as a possible etiological factor in bronchiogenic carcinoma. $7 A M A$ 1950;143:329-36.

2 Doll R, Hill AB. Smoking and carcinoma of the lung. BMF 1950;30:739.

3 Klaidman S. Health in the headlines: the stories behind the stories. New York: Oxford University Press, 1991.

4 Glantz SA, Slade J, Bero LA, et al. The cigarette papers. Berkeley, California: University of California Press, 1996.

5 Warner KE. Cigarette advertising and media coverage of smoking and health. N Engl f Med 1985;312:384-8.

6 Trichopoulos D, Kalandidi A, Sparros L, et al. Lung cancer and passive smoking. Int $\mathcal{F}$ Cancer 1981;27:1-4.

7 Hirayama T. Non-smoking wives of heavy smokers have a higher risk of lung cancer: a study from Japan. $B M \mathcal{F}$ (Clinical Research ed) 1981;282:183-5.

8 US Department of Health and Human Services. The health consequences of involuntary smoking. A report of the Surgeon General, 1986. Rockville, Maryland: Public Health Service, Centers for Disease Control, 1986. (DHHS Publication No (CDC) 87-8398.)

9 National Academy of Sciences. Environmental tobacco smoke: measuring exposures and assessing health effects. Washington, measuring exposures and assessing health

10 Wells AJ. Passive smoking as a cause of heart disease. $7 \mathrm{Am}$ Coll Cardiol 1994;24:546-54.

11 Steenland K. Passive smoking and the risk of heart disease. 7AMA 1992;267:94-9.

12 Glantz SA, Parmley WW. Passive smoking and heart disease: epidemiology, physiology and biochemistry. Circulation 1991;83:1-12.

13 US Environmental Protection Agency. Respiratory health effects of passive smoking: lung cancer and other disorders. Washington, DC: Office of Health and Environmental Assessment, 1992. (Publication No EPA/600/6-90/006F.)

14 Nelkin D. Selling science: how the press covers science and technology. New York: WH Freeman, 1987.

15 Moore M, ed. Health risks and the press: perspectives on media coverage of risk assessment and health. Washington, DC: Media Institute, 1989.

16 Koren G, Klein N. Bias against negative studies in newspaper reports of medical research. $\mathscr{f} A M A$ 1991;266:1824-6.

17 Conrad P. Media images, genetics and culture: potential impacts of reporting scientific findings on bioethics. Boston, Massachuof reporting scientific findings on bioeth

18 Bero L, Galbraith A, Rennie D. Sponsored symposia on environmental tobacco smoke. $\mathscr{f} A M A$ 1994;271:612-17.

19 Barnes D, Bero L. Why review articles on the health effects of passive smoking reach different conclusions. $\mathcal{F} A M A$ 1998;279:1566-70

20 Barnes D, Bero L. Scientific quality of original research articles on environmental tobacco smoke. Tobacco Control 1997;6:19-26.

21 Amos A, Jacobson B, White P. Cigarette advertising policy and coverage of smoking and health in British women's magazines. Lancet 1991;337:93-6.

22 Whelan E, Sheridan M, Meister K, et al. Analysis of coverage of tobacco hazards in women's magazines. 7 Public Health Policy 1981;Mar:29-35.

23 Krippendorff K. Content analysis. In: Kline FG, ed. The Sage Comm Text series, vol 5. Beverly Hills, California: Sage, 1980.

24 Weber RP. Basic content analysis. In: Lewis-Beck MS, ed. Quantitative applications in the social sciences, 2 nd ed. Series Q7-049). Newbury Park, New Jersey: Sage, 1990.

25 Ulrich's International Periodicals Directory. The Bowker International Serials Database, vol 4. New Providence, New Jersey: RR Bowker, 1997.

26 Bero LA, Glantz SG. Tobacco industry response to a risk assessment of environmental tobacco smoke. Tobacco Control 1993;2:103-13.

27 Barnes DE, Bero LA. Industry-funded research and conflict of interest: an analysis of research sponsored by the tobacco industry through the Center for Indoor Ai Research. $\mathcal{F}$ Health Polit Policy Law 1996;21:515-42.

28 Goldsmith MF. More magazines forgo tobacco ads, some by choice, some by chance. $7 A M A$ 1994;271:571-6.

29 Huber GL, Brockie RE, Mahajan VK. Passive smoking: how great a hazard? Consumers' Research 1991 Jul:10-15.

30 Huber GL. Passive smoking and your heart. Consumers' Research 1992 Apr:33-4.
31 Heath GW. When smoke gets in your eyes; passive smoking as a link to health problems for nonsmokers. Vibrant Life 1993 Sep: 12

32 Sullum J. Just how bad is secondhand smoke? National Review 1994 May 16:51

33 Koop CE. Non-smokers: time to clear the air. Readers Digest 1987 Apr:110-13.

34 Etzel RA, Trubo R. Hazards of "secondary smoke": effects of cigarettes on children. Good Housekeeping 1993 Sep:174, 218-19.

35 Penn A, Snyder CA. Inhalation of sidestream cigarette smoke accelerates development of arteriosclerotic plaques. Circulation 1993;88:1820-5.

36 Penn A, Chen LC, Snyder CA. Inhalation of steady-state sidestream smoke from one cigarette promotes development of arteriosclerotic plaque development. Circulation ment of arterios

37 Rajini P, Last JA, Pinkerton KE, et al. Decreased fetal weights in rats exposed to sidestream cigarette smoke. Fundam Appl Toxicol 1994;22:400-4.

38 Joad JP, Pinkerton KE, Bric JM. Effects of sidestream smoke exposure and age on pulmonary function and airway reactivity in developing rats. Pediatr Pulmonol 1993;16:281-8.

39 Ji CM, Plopper CG, Witschi HP, et al. Exposure to sidestream cigarette smoke alters bronchiolar epithelial cell differentiation in the postnatal rat lung. Am $\mathcal{F}$ Respir Cell Mol Biol 1994;11:312-20.

40 Hedge A, Erickson WA, Rubin G. The effects of alternative smoking policies on indoor air quality in 27 office buildings. Ann Occup Hyg 1994;38:265-78.

41 Matsukura S, Taminato $\mathrm{T}$, Kitano $\mathrm{N}$, et al. Effects of environmental tobacco smoke on urinary cotinine excretion in nonsmokers. Evidence for passive smoking. $N \mathrm{Engl}$ f Med 1984;311:828-32.

42 Coggins C, Ayres PH, Mosberg AT, et al. Subchronic inhalation study in rats using aged and diluted sidestream smoke from a reference cigarette. Inhalation Toxicology 1993;5:77-95.

43 Lee P, Chamberlain J, Alderson M. Relationship of passive smoking to risk of lung cancer and other smokingassociated diseases. Br 7 Cancer 1986;54:97-105.

44 Gori GB. Cancer risk assessment: the science that is not. Regul Toxicol Pharmacol 1992;16:10-20.

45 Perry R, Kirk PWW, eds. Indoor and ambient air quality. London: Selper, 1988

46 Lehnert G, Wynder EL, eds. Medical perspectives on passive smoking. Prev Med 1984;13:557.

47 Ecobichon DJ, Wu JM. Environmental tobacco smoke. Proceedings of the International Symposium at McGill University, Montreal, Canada. Lexington, Massachusetts: Lexington Books, 1990.

48 Tobacco Institute. Tobacco smoke and the non-smoker: scientific integrity at the crossroads. Washington, DC: Tobacco Institute, 1986.

49 Tollison RD. Smoking and society: towards a more balanced assessment. Massachusetts: DC Heath, 1986.

50 Varela L. Assessment of the association between passive smoking and lung cancer. New Haven, Connecticut: Yale University, 1987.

51 Harrison K, Hoberg G. Setting the environmental agenda in Canada and the United States: the cases of dioxin and radon. Can F Polit Sci 1991;24:3-27.

52 Jordan DL. Newspaper effects on policy preferences. Public Opinion Q 1993;57:191-204.

53 Winsten JA. Science and the media: the boundaries of truth. Health Affairs 1985;4:5-23.

54 Phillips DP, Kanter EJ, Bednarczyk B, et al. Importance of the lay press in the transmission of medical knowledge to the lay press in the transmission of medical knowledge to

55 Pini P. Media wars. Lancet 1995;346:1681-3.

56 Entwistle V. Reporting research in medical journals and newspapers. $B M \mathcal{F} 1995 ; 310: 920-3$.

57 Ratzan S. Health communication ethics (editorial). $\mathcal{f}$ Health Commun 1998;3:291-4.

58 Holcomb LC. Indoor air quality and environmental tobacco smoke-concentration and exposure. Environ Int 1993; 19:9-40.

59 Anon. Issue strategy background. RJ Reynolds, 1989. Bates 50761 2180. www.tobaccoresolution.com, RJR page. Accessed 16 July 1998.

60 Burns RB, Moskowitz MA, Osband MA, et al. Newspaper reporting of the medical literature. F Gen Intern Med 1995; 10:19-24.

61 Bero LA, Jadad A. How patients and policy makers can use systematic reviews for decision-making. Ann Int Med 1997;127:37-42.

62 Bero LA, Glantz SA, Rennie D. Publication bias and public health policy on environmental tobacco smoke. $\mathscr{f} A M A$ 1994;272:133-6.

63 Chapman S. The news on smoking: newspaper coverage of smoking and health in Australia, 1987-88. Am f Public Health 1989;79:1419-21. 